\title{
Quantification at the Syntax-Semantics Interface: Greek Every N Ps (University of Patras, 2014)
}

\author{
Anna-Maria Margariti \\ Independent Scholar, Athens \\ margaritianna@yahoo.com
}

\begin{abstract}
This dissertation offers a thorough examination of the Modern Greek distributive determiner. Specific focus is placed on particular parameters that involve whole sentences, which seem to result in different readings (semantic interpretations). I conclude through my analysis, which is circumscribed within the syntax-LF interface, that a common mechanism of Agree/binding is responsible for the emergence of these different readings.
\end{abstract}

\section{Keywords}

minimalism - quantification - syntax - semantics - interfaces - universal operator free choice - agree

A basic tenet of the Minimalist Program is that language connects the sensorymotor (Phonological Form or PF) and conceptual-intentional (Logical Form or LF) systems, innate in all human beings, and that it interacts with them in order to produce a linguistic expression (Chomsky 2000). Grammar or narrow syntax constructs expressions that are fed to the levels of PF (through Spell-Out) and LF. It is the latter, the narrow syntax-LF interface that constitutes the main focus of the present dissertation, in particular with regards to quantification, a phenomenon that is the root cause for the very positing of LF as a (then) "level of representation" (May 1977). Research on this particular two-interface area has not been very extensive, especially with regards to the syntactic analysis of rel- 
evant empirical data that give rise to more than one readings. The present work purports to contribute towards a better understanding of the role of syntax in quantificational phenomena as well as of any relevant syntax-LF interaction.

The present dissertation offers a thorough examination of the Modern Greek distributive determiner (o) kathe (every, each, any) nominal phrases (NPs) and accounts for the different readings of these expressions. Kathe NPs exhibit a universal distributive every reading (definite use), a Free Choice any (indefinite use) and a kind interpretation. $O$ kathe N Ps exhibit a universal distributive each reading (familiar and definite use), a Free Choice any and an Indiscriminative Free Choice just any reading (indefinite uses). The ambiguous behavior of English every NPs is also discussed and accounted for, along with the double readings of Greek $o$, $i$, to ('the') NPs, among others, as they all seem to fall within the premises of the same theoretical explanation.

The examination focuses on particular parameters which involve the whole sentence and which seem to affect the emergence of each different reading, such as modification, determiner spreading, but also lexical as well as grammatical aspect and tense. Hence the analysis, circumscribed within the syntax-LF interface, points towards a common mechanism of Agree / binding that seems to underlie the emergence of this whole range of different interpretations. In Chapter 1, I present the essential syntactic and semantic background, as well as an outline of my proposal to the riddle of every and (o) kathe NPs interpretational variability. In Chapter 2, I discuss and analyze the syntax of Determiner Phrases and Quantifier Phrases and in particular the syntactic structure of Greek kathe, o kathe, oli $i$ NPs, as well as that of English every, each, all and all the NPs. In Chapter 3 I investigate the different readings the kathe and $o$ kathe NPs give rise to and the semantics behind that, as well as previous approaches on the issue. In Chapter 4, I explain the interpretational variability of the expression in hand as a result of the binding of the NPs' context set variables by different Operators (a Definiteness, a Generic or a Modal Operator) and Operation Agree. In Chapter 5, I discuss how the theory proposed for Greek kathe, o kathe and English every, each NPs could explain relevant phenomena of quantificational variability in Chinese and Japanese, as well as Greek Polarity phenomena. In Chapter 6, I conclude the discussion.

Following the standard assumptions of Generalized Quantifiers in logic (Mostowski 1957) and in the ensuing semantic tradition (Montague 1973), universal quantification has been unanimously regarded by linguists as implicating the 
presence of a universal operator either within the lexical determiner (as in Barwise \& Cooper 1981, Keenan 2003, among many others) or, if not there, at least as a sentential Operator at LF / Syntax (as in Szabolcsi 2010). Under the former view, every and kathe NPs should exhibit a uniform, universally quantified interpretation. However, a closer look at the data indicates that every also exhibits non-universal readings (examples 3 and 4 from Beghelli \& Stowell 1997:101:41 and Schwartzchild 1996: 78: 185, respectively):

(1) Every dog has a tail.

(2) Each dog has a tail.

(3) For the most part, John knows which book every student bought.

(4) One out of every three handguns in America is made by Smith and Wesson.

Every NPs may have a kind as well as a universal interpretation (1), an interpretation more close to most as in (3) and a partitive use as in (4). Each NPS, on the other hand, exhibit a Universal-only interpretation as in (2). On the other hand, plural indefinites also exhibit a distributive yet not universal reading:

(5) Two friends had three pizzas and a glass of beer.

All the above data indicate that every N Ps are not always interpreted universally and that distribitivity exists independently from universal quantification (as in Beghelli \& Stowell's 1997 "pseudo-distributivity" and Szabolcsi's 2010 view on every NPs). Modern Greek kathe NP data are more generous in number and clarity of different readings:

(6) Kathe mathitis pire tria vivlia. Universal only every student took.3sg three books.

'Every student took three books.'

(7) Kathe ghata exi tesera podhia. Kind every cat has.3sg four feet 'Every cat has four feet.'

(8) Kathe etisi tha meletithi every petition will be-studied.3sG dhieksodhika. Free Choice any / Universal reading thoroughly

'Any / every petition will be thoroughly examined.' 
As observed from the translations, kathe NPs in Modern Greek may render three different readings: a universal distributive one as in (6) and (8), a kind reading as in (7) and a Free Choice any NP reading as a second reading in (8). A similar situation is attested with $o$ kathe (commonly translated as each) as in (9), except that the kind reading is not an available option (as in 9), while there's an extra Indiscriminative Free Choice (Horn 200o) reading available (10):

(9) I kathe ghata exi tesera podhia. *Kind/Universal the every cat has.3sg four feet 'Each cat has four feet.'

(10) Stin eurovision bori na traghudhisi o kathe at the eurovision can.3sg sing.3sg the every asxetos. FCI indiscriminative irrelevant 'Just any amateur can sing at the eurovision (contest).'

Lexical aspect $(11,12)$ as well as grammatical aspect (for Greek as well as English) and tense (13 and 14) play a role. In (13) we may only have a universal interpretation, whereas in (14) we may have either a universal or a Free Choice interpretation for the expression in question:

(11) *Kathe mathitis ine poliplithis.

Every student is numerous

(12) *Every student is numerous.

(13) Kathe mathitis me pire tilefono.

Kathe student me took.PERF. telephone

'Every student called me.'

(14) Kathe mathitis me eperne tilefono.

kathe student me took-IMP. telephone

'Every / any student could call / had the habit of calling me.'

The analysis leads to the following results and proposals: Kathe /every are not endowed with inherent quantificational force. They carry a distributive feature that has to Agree with a sentential distributive operator in C. Distributivity is distinct from Universal Quantification. The latter ensues as a combination of distributivity and definiteness. Each is specified for both. Kathe NPs quantifica- 
tion involves different Operators at $\mathrm{C}$ ranging over the whole sentence, the VP as well as the NP, giving rise to the different interpretations each time.

\section{Conclusion}

The analysis suggests that kathe as well as every determiners do not lexicalize a universal operator. Following Szabolcsi (2010) on every NPs, I argue that (o) kathe NPs are (inherently) indefinite expressions (in the sense of Heim 1982) that make part of a quantificational concord. A distributive operator binds the element variables of their NP set and (sub) events variables on AspP; a Definiteness, a Generic or a Modal Operator binds the context set variables of the NP, rendering a universal, a kind or an FC reading to the expression, accordingly, and time variables on TP. The presence of different sentential operators under $\mathrm{C}$ determines the readings that arise. I argue that binding by these operators corresponds to two Agree operations in syntax: One is between the Distributive operator in C and Q on the DP as well as with Aspect on the vP. The other one is between the sentential operator and the relevant feature on $\mathrm{Q}$, but also on TP. The quantificational chains formed are argued to be, to some extent, similar to that of $w h$-chains.

\section{References}

Barwise, Jon and Robert Cooper. 1981. Generalized Quantifiers and Natural Language. Linguistics and Philosophy 4, 159-219.

Beghelli, Filippo and Tim Stowell. 1997. Distributivity and Negation: The syntax of each and every. In A. Szabolcsi (ed.), Ways of Scope Taking. Dordrecht: Kluwer, 71-107.

Horn, Larry. 2000. Pick a Theory: Not Just Any Theory. In Laurence Horn and Yasuhiko Kato (eds.), Negation and Polarity: Syntactic and Semantic Perspectives, 147-192. Oxford: Oxford University Press.

Keenan, Edward. L. 2003. The Definiteness effect: semantics or pragmatics? Natural Language Semantics 11, 187-216.

May, Robert. 1977. The Grammar of Quantification. Ph.D. dissertation, MIT.

Montague, Richard. 1974. Richmond Thomason (ed.). Formal Philosophy: Selected Papers of Richard Montague. New Haven and London: Yale University Press.

Mostowski, Andrea. 1957. On a generalization of quantifiers. Fundamenta Mathematica. $44,12-36$.

Schwarzschild, Robert. 1996. Pluralities. Dordrecht: Kluwer Academic Publishers.

Szabolcsi, Anna. 2010. Quantification. (Research Surveys in Linguistics). Cambridge: Cambridge University Press. 